Navigation Physics 2(1) (2020)
Navigation Physics
Journal of Physics Education

\title{
Media Analisis Rangkaian Listrik Menggunakan Pendekatan Numerik Gauss-Jordan, Gauss-Seidel, dan Cramer
}

\author{
Nurullaeli $^{1^{*}}$ \\ ${ }^{1}$ Universitas Indraprasta PGRI Jakarta \\ *E-mail: 1eli.biofisika@gmail.com
}

\begin{tabular}{|c|c|}
\hline Info Artikel & Abstract \\
\hline $\begin{array}{l}\text { Keywords: } \\
\text { Analysis media, Gauss-Jordan, Gauss- } \\
\text { Seidel, Cramer }\end{array}$ & $\begin{array}{l}\text { The aim of this study is create an analysis media for calculating the electric } \\
\text { current in a closed circuit with one or more loops. Gauss-Jordan, Gauss- } \\
\text { Seidel, and Cramer methods were used in this study. This media is } \\
\text { packaged into Graphic User Interface (GUI) with matlab language } \\
\text { program assisting. In this study, Linear Equation System (SPL) was } \\
\text { obtained from kirchhoff current law and kirchhoff voltage law concepts. } \\
\text { Gauss-Seidel method is not always convergent for each formed SPL, } \\
\text { because it can only be applied when coefficient matrix A was diagonally } \\
\text { dominant. The application of this analysis media made the calculation of } \\
\text { closed circuit electric current with one or more loops became accurate and } \\
\text { time saving. }\end{array}$ \\
\hline
\end{tabular}

How to Cite: Nurullaeli, N. (2020). Media analisis rangkaian listrik menggunakan pendekatan numerik Gauss-Jordan, Gauss-Seidel, dan Cramer. Navigation Physics, 2 (1): 1-8.

\section{PENDAHULUAN}

Saat ini metode numerik banyak digunakan dalam berbagai disiplin ilmu, tidak terkecuali dalam ilmu fisika. Metode numerik digunakan untuk mempermudah mendapatkan solusi persamaan yang sulit diselesaikan secara analitik atau bahkan persamaan yang tidak dapat diselesaikan secara analitik. Metode numerik adalah teknik-teknik yang digunakan untuk memformulasikan masalah matematis agar dapat dipecahkan dengan operasi perhitungan (Setiawan, 2006: 25). Perhitungan dalam metode numerik melibatkan sejumlah besar operasi hitungan yang berulang (Nasution dkk, 2017:71).

Hukum kirchoff merupakan salah satu hukum yang digunakan dalam menyelesaikan persoalan rangkaian listrik. Hukum kirchoff terbagi menjadi dua macam, yaitu Kirchhoff Current Law atau KCL dan Kirchhoff Voltage Law atau KVL (Warnes, 1994). Persamaan hukum kirchoff untuk rangkaian listrik merupakan SPL. Suatu persamaan linear dalam $\mathrm{n}$ variabel $\mathrm{x}_{1}, \mathrm{x}_{2}, \ldots, \mathrm{x}_{\mathrm{n}}$ merupakan suatu persamaan dalam bentuk $\mathrm{a}_{1} \mathrm{x}_{1}+\mathrm{a}_{2} \mathrm{x}_{2}+\ldots+\mathrm{a}_{\mathrm{n}} \mathrm{x}_{\mathrm{n}}=\mathrm{b}$ dan $\mathrm{b}$ adalah konstanta real. Sejumlah persamaan linear yang banyaknya berhingga dalam variabel $\mathrm{x}_{1}, \mathrm{x}_{2}, \ldots, \mathrm{x}_{\mathrm{n}}$ disebut SPL (Anton \& Rorres, 2004). Penyelesaian persamaan tersebut dapat dilakukan secara analitik, tetapi ketika rangkaian listrik rumit dan terdiri dari banyak loop perhitungan analitik tidak mudah dilakukan dan memerlukan waktu yang lama. Kesalahan perhitungan sering tidak terhindarkan dan mahasiswa harus menghitung kembali dari awal sehingga dapat menurunkan minat mahasiswa dalam belajar penerapan hukum kirchoff. Tingkat kesalahan yang tertinggi (90\%) adalah perhitungan arus listrik pada rangkaian tertutup dengan dua buah loop dan lebih dari satu buah sumber tegangan serta hambatan (Wahyudi, 2015: 134).

Alternatif media analisis rangkaian listrik pada rangkaian tertutup untuk satu loop atau lebih diperlukan agar mahasiswa lebih mudah menghitung arus listrik dari SPL yang sudah mereka dapatkan saat mengerjakan soal sehingga mereka dapat belajar dengan lebih efektif dan efisien. Media ini juga diperlukan mereka saat melakukan percobaan yang berkaitan dengan hukum kirchoff dimana perhitungan yang harus mereka lakukan cukup banyak dan membutuhkan ketelitian yang tinggi. Dalam penelitian ini peneliti membuat media analisis rangkaian listrik menggunakan pendekatan metode Gauss- 
Jordan, Gauss-Seidel, dan Cramer. Media analisis rangkaian listrik dikemas dalam bentuk GUI yang menarik dan mudah digunakan.

\section{METODE PENELITIAN}

Kegiatan penelitian ini melalui beberapa tahapan, yaitu studi pustaka, analisis numerik rangkaian listrik, dan analisis sistem fisis.

\section{A. Studi Pustaka}

Studi pustaka dilakukan untuk memahami metode Gauss-Jordan, metode Gauss-Seidel, metode Cramer, konsep penerapan hukum kirchoff dalam perhitungan arus listrik pada rangkaian tertutup dengan satu buah loop atau lebih, serta mengetahui sejauh mana perkembangan dari bidang yang diteliti.

\section{B. Analisis Numerik Rangkaian Listrik}

Analisis numerik digunakan untuk menghitung arus listrik pada rangkaian tertutup dengan satu buah loop atau lebih. Analisis ini dikemas dalam bentuk GUI dengan bantuan software Matlab R2013a. Analisis numerik ini menggunakan beberapa pendekatan, yaitu:

1. Metode Gauss-Jordan

Metode ini diberi nama Gauss-Jordan untuk menghormati Carl Friedrich Gauss dan Wilhelm Jordan. Metode ini sebenarnya adalah modifikasi dari metode eliminasi gauss, yang dijelaskan oleh Jordan di tahun 1887. Dalam eliminasi Gauss-Jordan, matriks A dieliminasi menjadi matriks identitas I. Solusinya langsung diperoleh dari vektor kolom $b$ hasil proses eliminasi.

$$
A x=b \rightarrow I x=b^{\prime}
$$

Dalam bentuk matrik, eliminasi Gauss-Jordan ditulis sebagai:

$$
\left[\begin{array}{cccc|c}
a_{11} & a_{12} & \ldots & a_{1 n} & b_{1} \\
a_{21} & a_{22} & \ldots & a_{2 n} & b_{2} \\
\ldots & \ldots & \ldots & . & \ldots \\
\ldots & \ldots & \ldots & . & \ldots \\
a_{n 1} & a_{n 2} & \ldots & a_{n m} & b_{n}
\end{array}\right] \rightarrow\left[\begin{array}{ccccc|c}
1 & 0 & 0 & \ldots & 0 & b_{1}^{\prime} \\
0 & 1 & 0 & \ldots & 0 & b_{2}^{\prime} \\
\ldots & \ldots & \ldots & \ldots & \ldots & \ldots \\
\ldots & \ldots & \ldots & \ldots & \ldots & \ldots \\
0 & 0 & 0 & \ldots & 1 & b_{n}^{\prime}
\end{array}\right]
$$

(Rahayu, 2011).

2. Metode Gauss-Seidel

Sistem Persamaan Linear dalam bentuk persamaan perkalian matriks dapat ditulis

$$
A_{x}=b
$$

dengan asumsikan bahwa matriks $\mathrm{A}$ adalah matriks nonsingular, dan semua elemen diagonalnya tidak ada yang nol. Maka matriks A diberi pemisah (splitting) yaitu

$$
A=D-E-F
$$

dengan $\mathrm{D}$ adalah matriks diagonal dari $\mathrm{A}, \mathrm{E}$ adalah matriks segitiga bawah dari $\mathrm{A}$,dan $\mathrm{F}$ adalah matrik segitiga atas dari A. Maka metode Gauss-Seidel untuk persamaan (3) didefinisikan sebagai berikut

$$
x^{(k+1)}=(D-E)^{-1} F x^{(k)}+(D-E)^{-1} b
$$

Metode iterasi Gauss-Seidel dengan nilai aproksimasi akan konvergen pada sebarang tebakan awal $x 0$. Dengan syarat A matriks simetris positif. Namun metode iterasi Gauss-Seidel konvergennya masih dinilai lambat (Ramadhan dkk, 2014: 351-352)

\section{Metode Cramer}


Aturan Cramer merupakan salah satu metode yang biasa digunakan untuk menyelesaikan SPL dengan memanfaatkan determinan dari matriks koefisien dari SPL. Akan tetapi untuk menghitung penyelesaiannya, harus menghitung $\mathrm{n}+1$ banyaknya determinan dari matriks berordo $\mathrm{n} \times \mathrm{n}$. Aturan Cramer berguna untuk mempelajari sifat-sifat matematika dari suatu penyelesaian tanpa perlu menyelesaikan sistem secara keseluruhan. Suatu SPL dapat dinyatakan ke dalam bentuk persamaan $\mathrm{Ax}=\mathrm{b}$. Apabila $\operatorname{det}(\mathrm{A}) \neq 0$, maka A punya invers, sehingga penyelesaian dari SPL dapat ditentukan dengan $x=A^{-1} b$, sehingga mengakibatkan $x_{i}=\frac{A_{i}}{|A|}$ (Saragih dkk, 2012: 3).

Sebelum menggunakan media analisis, pengguna harus melakukan analisis pendahuluan untuk mendapatkan SPL rangkaian yang akan dicari arus listriknya. SPL yang didapatkan dari analisis pendahuluan ditulis dalam bentuk matrik sebagai berikut

$$
\left[\begin{array}{cccc}
A_{11} & A_{12} & \ldots \ldots & A_{1 n} \\
A_{21} & A_{22} & \ldots \ldots & A_{2 n} \\
\ldots . . & \ldots \ldots & \ldots . . & \ldots . . \\
A_{m 1} & A_{m 2} & \ldots \ldots & A_{m n}
\end{array}\right]\left[\begin{array}{c}
I_{1} \\
I_{2} \\
\ldots \ldots \\
I_{n}
\end{array}\right]=\left[\begin{array}{c}
V_{1} \\
V_{2} \\
\ldots . \\
V_{m}
\end{array}\right]
$$

Matrik A menyatakan matrik koefisien, matrik I menyatakan matrik arus, dan matrik V menyatakan matrik beda potensial. Matrik A dan matrik V tersebut yang digunakan sebagai masukan dalam media analisis.

\section{Analisis Sistem Fisis}

Tahapan akhir dari penelitian ini, yaitu analisis sitem fisis dari hasil perhitungan media analisis yang telah dibuat.

\section{HASIL DAN PEMBAHASAN}

Media analisis rangkaian listrik pada penelitian ini terdiri dari satu buah jendela utama dan tiga buah jendela untuk menghitung arus listrik pada rangkaian tertutup dengan satu buah loop atau lebih. Pada jendela utama, pengguna dapat memilih metode analisis yang akan digunakan. Tampilan jendela utama dapat dilihat pada gambar 1 .

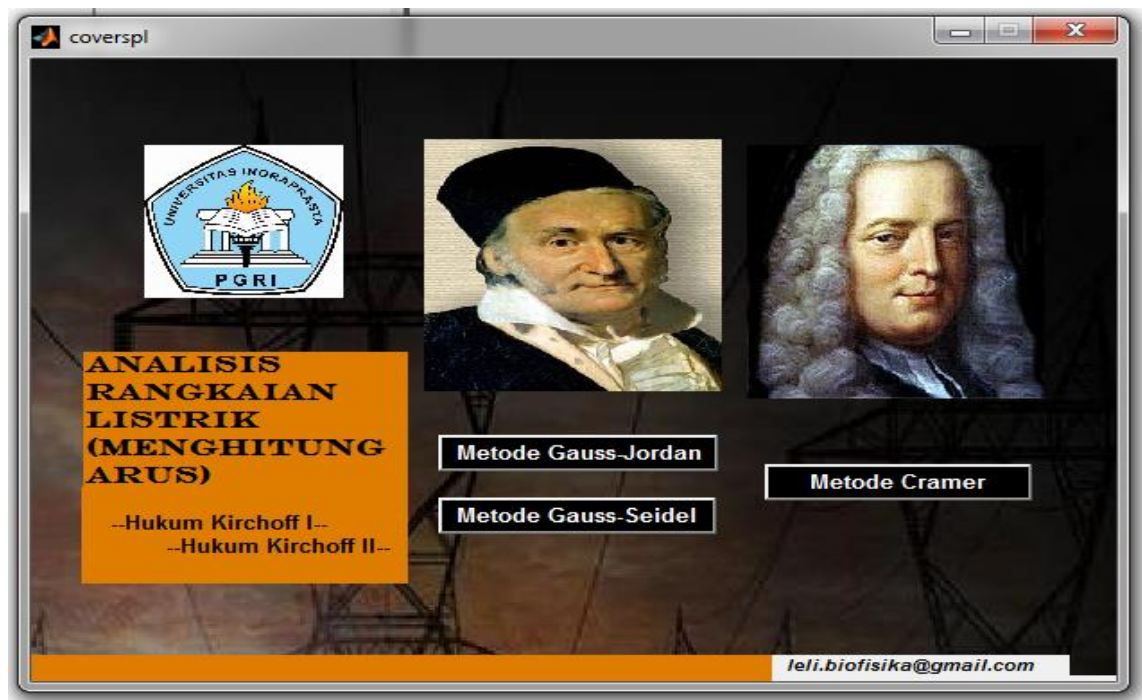

Gambar 1. Tampilan Jendela Utama Sumber: Peneliti

Sebelum menggunakan media analisis tersebut, pengguna diharuskan terlebih dahulu menentukan SPL dari rangkaian. SPL yang didapatkan ditulis dalam bentuk matrik AI = V. Matrik A dan V digunakan sebagai masukan dan matrik I merupakan solusi yang dicari. Jika ada soal rangkaian listrik yang terdiri 
dari lima buah resistor $\mathrm{R}_{1}=2 \Omega, \mathrm{R}_{2}=2 \Omega, \mathrm{R}_{3}=6 \Omega, \mathrm{R}_{4}=6 \Omega$, dan $\mathrm{R}_{5}=5 \Omega$ yang dihubungkan dengan tegangan 2 Volt seperti pada gambar 2.

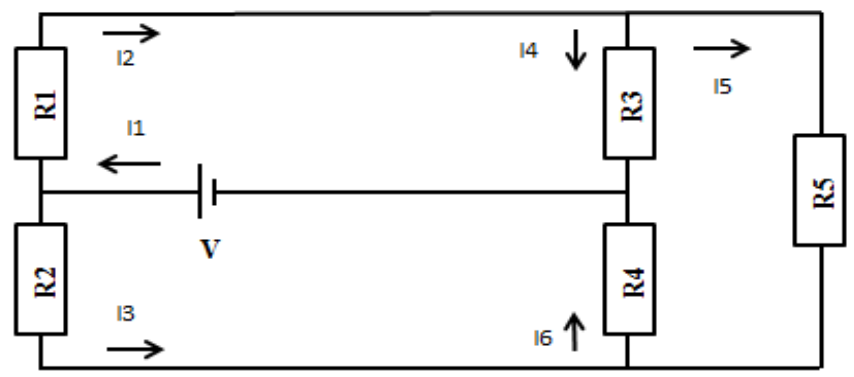

Gambar 2. Rangkaian Listrik Tiga Loop Sumber: Peneliti

Berdasarkan hukum kirchoff, dari rangkaian tersebut dapat ditulis dalam bentuk SPL sebagai berikut

$$
\begin{aligned}
& I_{3}+3 I_{6}=1 \\
& I_{2}+3 I_{4}=1 \\
& -6 I_{4}+5 I_{5}+6 I_{6}=0 \\
& I_{1}-I_{2}-I_{3}=0 \\
& I_{2}-I_{4}-I_{5}=0 \\
& -I_{3}-I_{5}+I_{6}=0
\end{aligned}
$$

SPL yang didapat ditulis dalam bentuk matrik

$$
\left[\begin{array}{cccccc}
0 & 0 & 1 & 0 & 0 & 3 \\
0 & 1 & 0 & 3 & 0 & 0 \\
0 & 0 & 0 & -6 & 5 & 6 \\
1 & -1 & -1 & 0 & 0 & 0 \\
0 & 1 & 0 & -1 & -1 & 0 \\
0 & 0 & -1 & 0 & -1 & 1
\end{array}\right]\left[\begin{array}{c}
I_{1} \\
I_{2} \\
I_{3} \\
I_{4} \\
I_{5} \\
I_{6}
\end{array}\right]=\left[\begin{array}{l}
1 \\
1 \\
0 \\
0 \\
0 \\
0
\end{array}\right]
$$

Matrik SPL ditulis ke dalam notepad dan kemudian disimpan dengan nama matrik1 untuk matrik koefisien A dan matrik2 untuk matrik V. Penulisan matrik koefisien A dan V seperti pada gambar 3.

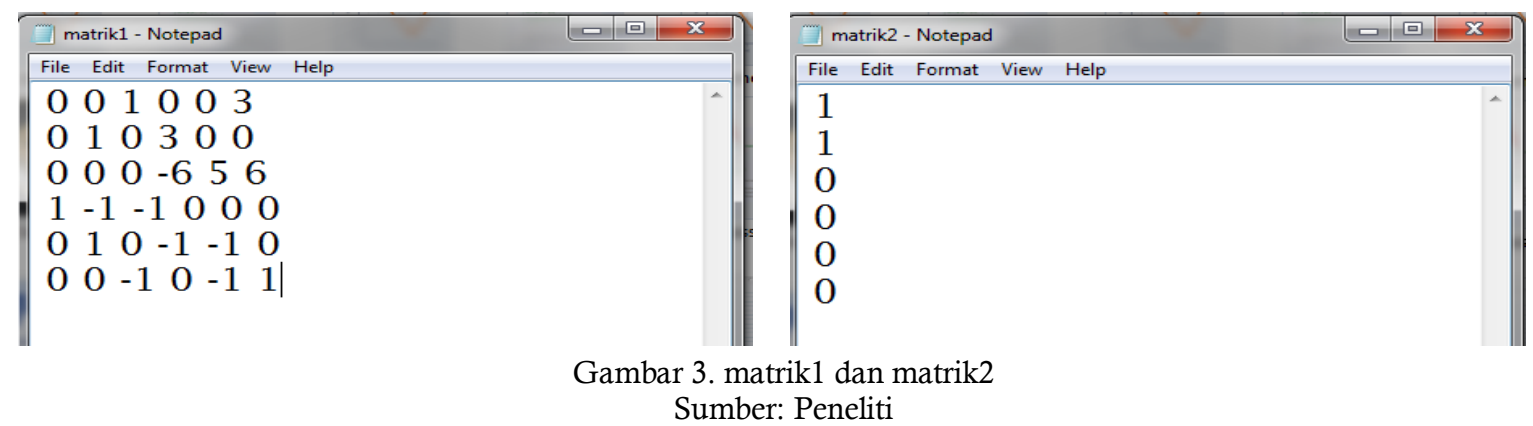

Pengguna dapat memilih metode yang digunakan dalam perhitungan arus listrik pada jendela utama dengan menekan tombol Metode Gauss-Jordan, Metode Gauss-Seidel, atau Metode Cramer. Pengguna tinggal memasukkan matrik koefisien A dengan menekan tombol Masukkan A dan memilih matrik1.txt, kemudian memasukkan matrik V dengan menekan tombol Masukkan V dan memilih matrik2.txt. Untuk proses perhitungan, pengguna menekan tombol PROSES. Hasil perhitungan akan muncul pada tabel Matrik I. Pada metode Gauss-Seidel dan metode Cramer, pengguna diharuskan 
memasukkan jumlah persamaan linear. Pada kiri atas jendela perhitungan arus listrik terdapat menu yang digunakan untuk memilih jendela mana yang akan selanjutnya dibuka. Analisis rangkaian listrik pada gambar 2 menggunakan metode Gauss-Jordan dapat dilihat pada gambar 4. Pada analisis menggunakan metode Gauss-Jordan didapatkan besar arus $\mathrm{I}_{1}=0.5 \mathrm{~A}, \mathrm{I}_{2}=\mathrm{I}_{3}=\mathrm{I}_{4}=\mathrm{I}_{6}=0.25 \mathrm{~A}$, dan $\mathrm{I}_{5}=0 \mathrm{~A}$.

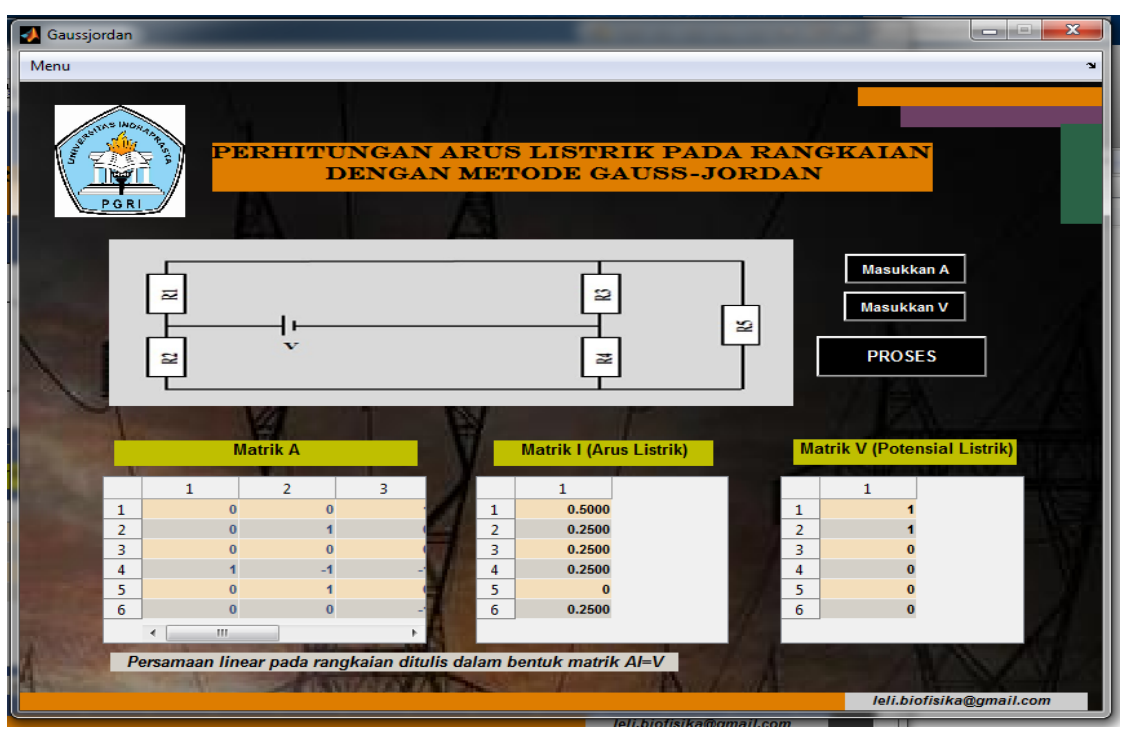

Gambar 4. Tampilan Jendela Perhitungan Arus Listrik pada Rangkaian Gambar 2 dengan Metode Gauss-Jordan. Sumber: Peneliti

Sedangkan analisis menggunakan metode Gauss-Seidel dapat dilihat pada gambar 5. Analisis rangkaian pada gambar 2 menggunakan metode ini tidak mendapatkan hasil dikarenakan matrik koefisien A pada SPL yang terbentuk tidak bersifat dominan kuat secara diagonal, sehingga metode Gauss-Seidel tidak konvergen. Sifat dominan kuat secara diagonal didapatkan ketika koefisien diagonal sama atau lebih besar dari jumlah semua koefisien baris tersebut dan minimal terdapat satu baris yang memiliki koefisien diagonal yang lebih besar dari jumlah koefisien baris tersebut.

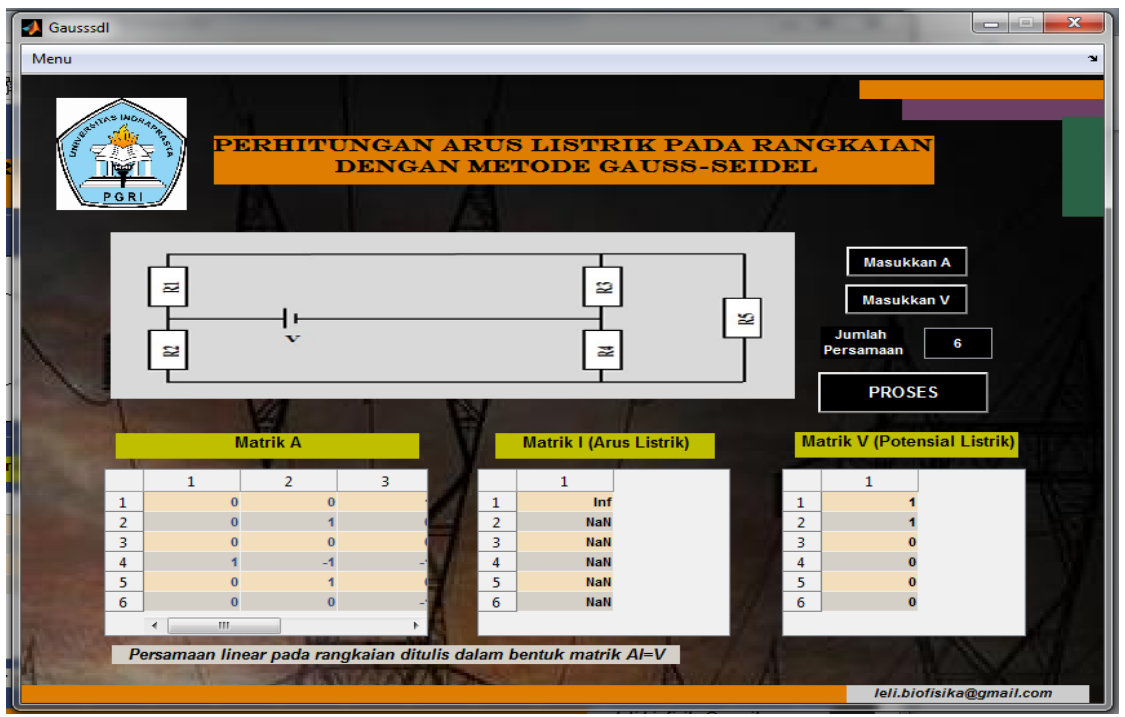

Gambar 5. Tampilan Jendela Perhitungan Arus Listrik pada Rangkaian Gambar 2 dengan Metode Gauss-Seidel. Sumber: Peneliti

Metode yang ketiga, yaitu metode Cramer. Perhitungan arus listrik menggunakan metode Cramer mendapatkan hasil yang sama dengan perhitungan arus listrik menggunakan metode Gauss-Jordan. Besar arus $\mathrm{I}_{1}=0.5 \mathrm{~A}, \mathrm{I}_{2}=\mathrm{I}_{3}=\mathrm{I}_{4}=\mathrm{I}_{6}=0.25 \mathrm{~A}$, dan $\mathrm{I}_{5}=0 \mathrm{~A}$. Tampilan jendela perhitungan arus listrik menggunakan metode Cramer dapat dilihat pada gambar 6. 


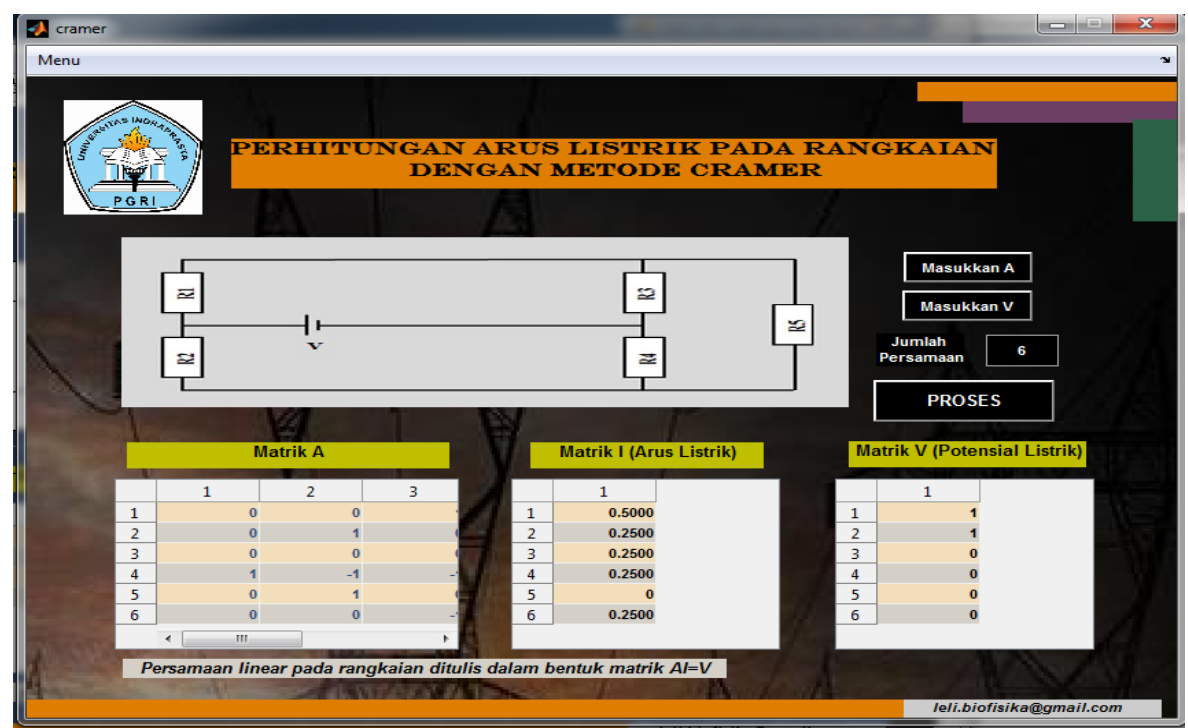

Gambar 6. Tampilan Jendela Perhitungan Arus Listrik pada Rangkaian Gambar 2 dengan Metode Cramer. Sumber: Peneliti

Media ini juga diuji untuk menghitung arus listrik pada rangkaian dua loop. Rangkaian listrik terdiri dari tiga buah resistor $\mathrm{R}_{1}=2 \Omega, \mathrm{R}_{2}=6 \Omega$, dan $\mathrm{R}_{3}=8 \Omega$ yang dihubungkan dengan tegangan $\mathrm{V}_{1}=24$ Volt, $\mathrm{V}_{2}=12$ Volt, dan $\mathrm{V}_{3}=32$ Volt seperti pada gambar 7 .

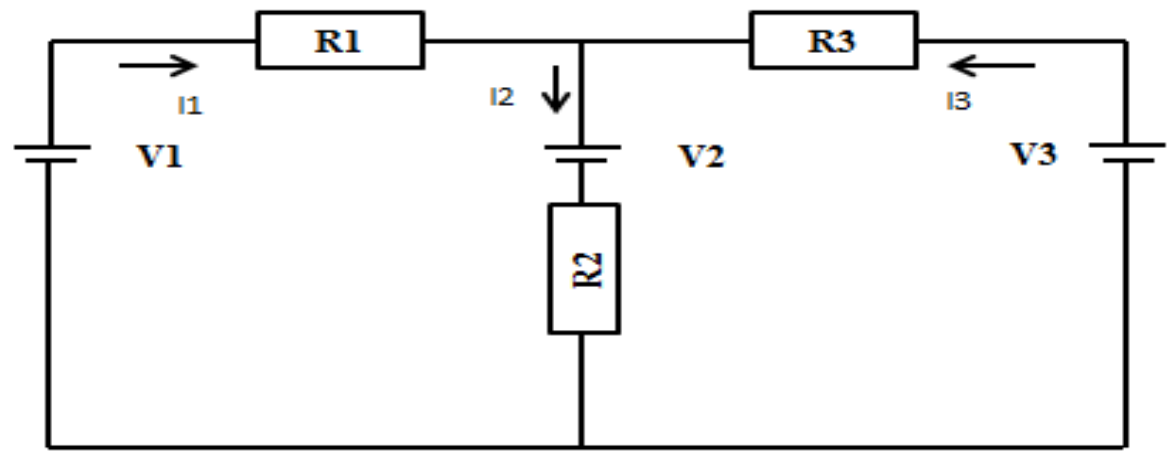

Gambar 7 . Rangkaian Listrik Dua Loop Sumber: Peneliti

Perhitungan arus listrik rangkaian dua loop pada gambar 7 menggunakan metode Gauss-Jordan, GaussSeidel, dan Cramer mendapatkan besar arus yang sama, yaitu $\mathrm{I}_{1}=0.6316 \mathrm{~A}, \mathrm{I}_{2}=1.7895 \mathrm{~A}$, dan $\mathrm{I}_{3}=$ 1.1579 A. Hasil perhitungan untuk metode Gauss-Jordan dapat dilihat pada gambar 8, metode GaussSeidel pada gambar 9, dan metode Cramer pada gambar 10. Hasil ini menunjukkan bahwa ketiga metode tersebut dapat digunakan untuk menghitung arus listrik pada rangkaian dua loop seperti kasus pada gambar 6 dikarenakan matrik koefisien A yang terbentuk mempunyai sifat dominan kuat secara diagonal. 


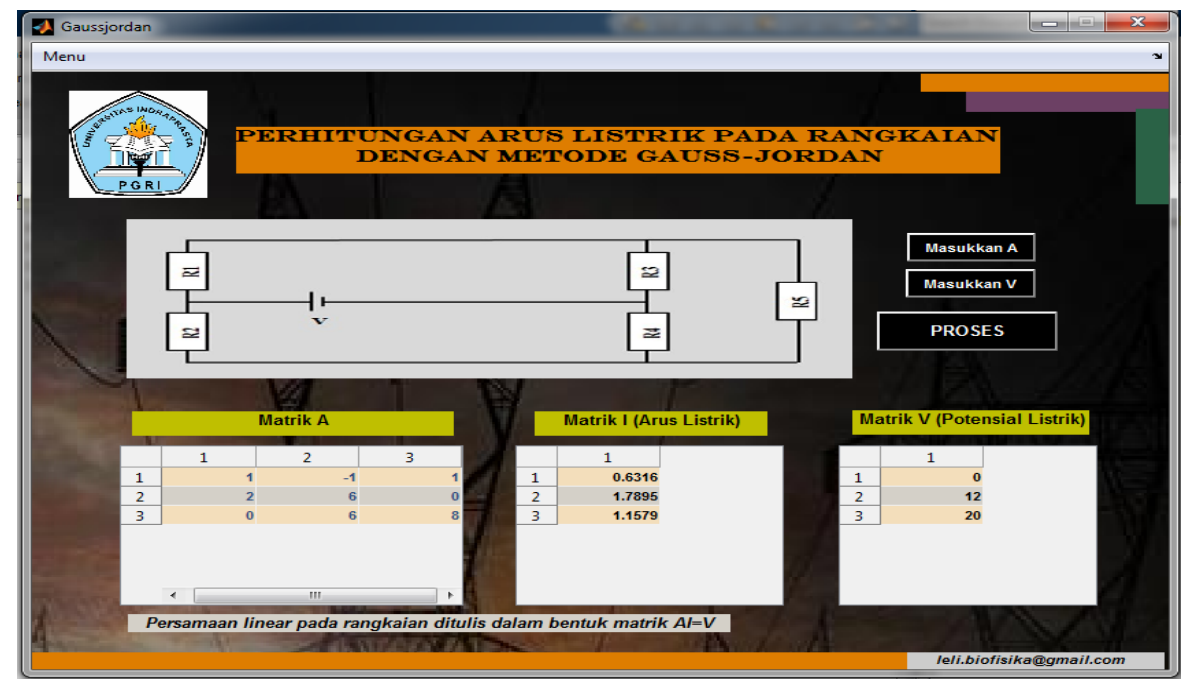

Gambar 8. Tampilan Jendela Perhitungan Arus Listrik pada Rangkaian Gambar 7 dengan Metode Gauss-Jordan. Sumber: Peneliti

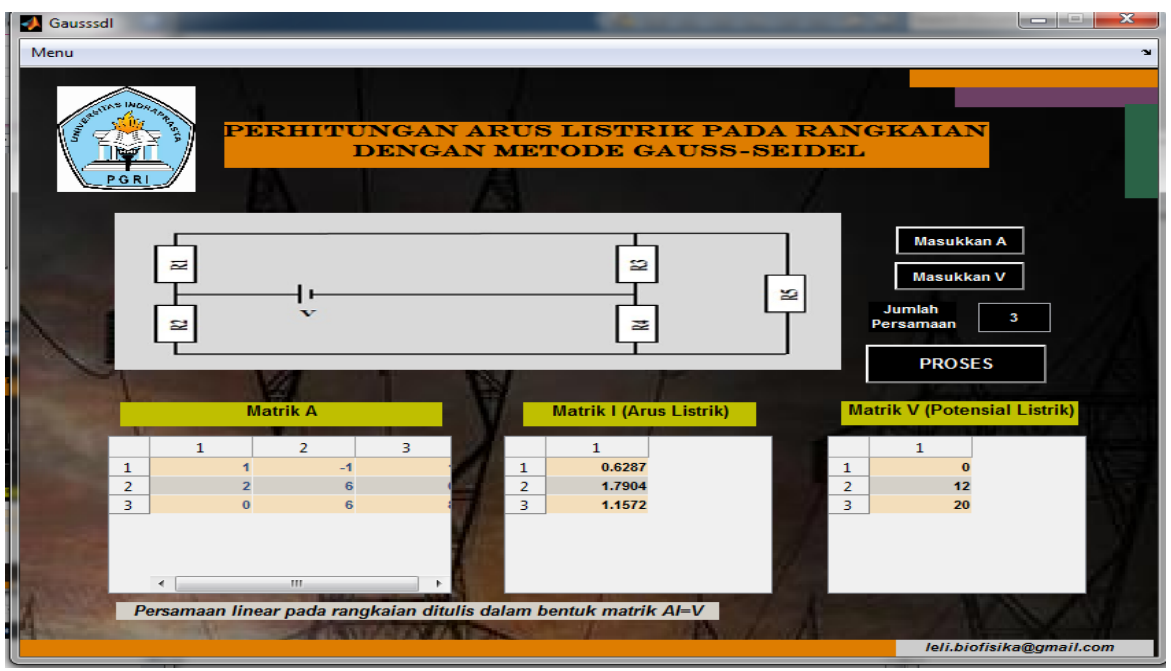

Gambar 9. Tampilan Jendela Perhitungan Arus Listrik pada Rangkaian Gambar 7 dengan Metode Gauss-Seidel. Sumber: Peneliti

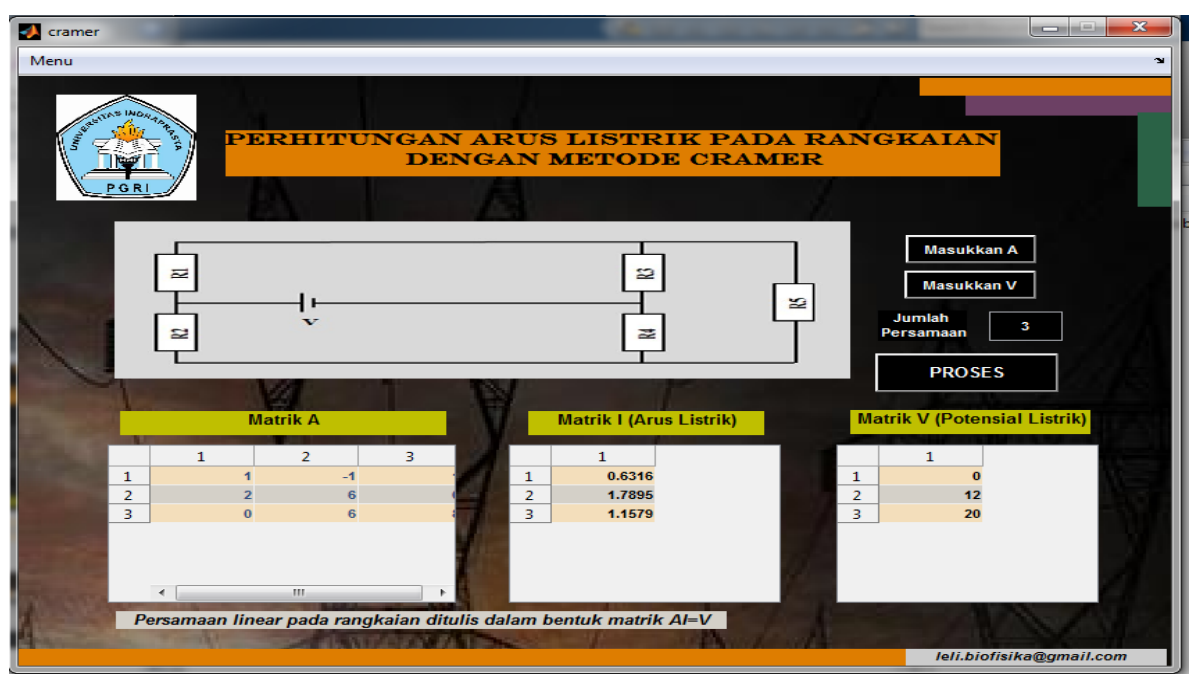

Gambar 10. Tampilan Jendela Perhitungan Arus Listrik pada Rangkaian Gambar 7 dengan Metode Cramer. Sumber: Peneliti 


\section{PENUTUP}

Media analisis rangkaian listrik menggunakan pendekatan metode numerik Gauss-Jordan, GaussSeidel, dan Cramer dapat digunakan untuk menghitung arus listrik pada rangkaian tertutup dengan satu loop atau lebih. Untuk metode Gauss-Seidel tidak selalu konvergen untuk setiap SPL. Metode GaussSeidel dapat diterapkan ketika matrik koefisien A bersifat dominan kuat secara diagonal. Penggunaan media analisis ini membuat perhitungan arus listrik lebih akurat dan menghemat waktu.

Adapun saran untuk penelitian selanjutnya, yaitu perlu adanya perhitungan besaran lain yang berkaitan dengan rangkaian listrik yang dianalisis. Selain itu, diperlukan adanya simulasi arus listrik agar tampilan media analisis lebih menarik dan mahasiswa lebih mudah memahami konsep penerapan hukum kirchoof pada rangkaian listrik satu loop atau lebih.

\section{DAFTAR PUSTAKA}

Anton, H, \& Rorres, C. (2004). Aljabar Linear Elementer Versi Aplikasi, Edisi Kedelapan. Jakarta: Erlangga.

Nasution, M. D., Nasution, E., \& Haryati, F. (2017). Pengembangan Bahan Ajar Metode Numerik dengan Pendekatan Metakognitif Berbantuan MATLAB. Mosharafa: Jurnal Pendidikan Matematika, 6(1), 69-80.

Rahayu, Y. (2011). Penerapan Metode Numerik Pada Peramalan Untuk Menghitung Koefisien-Koefisien Pada Garis Regresi Linear Berganda. Sematik, 1(1).

Ramadhan, A., Syamsudhuha, S., \& Sirait, A. (2014). Generalisasi metode Gauss-Seidel Untuk Menyelesaikan Sistem Persamaan Linear. JOM FMIPA, 1(2), 351-358.

Saragih, M. L. R., Aritonang, M., \& Irawan, B. (2012). Modifikasi Aritmetika Interval dan Penerapannya Pada Sistem PersamaanInterval Linear. Bimaster, 1(1), 1-8.

Setiawan, A. 2006. Pengantar Metode Numerik. Yogyakarta: PT Andi Offsett.

Wahyudi, W. (2017). Analisis Hasil Belajar Mahasiswa pada Pokok Bahasan Hukum Ohm dan Kirchoff dalam Matakuliah Elektronika Dasar I. Jurnal Pendidikan Fisika dan Teknologi, 1(2), 129-134.

Warnes, L. A. (1994). Electronic and Electrical Engineering: Priciples and Practice. London: Macmillan Press, Ltd. 